\title{
A Way Forward: Sustainable ICTs And Regional Sustainability'
}

\author{
Greg Hearn \\ Queensland University of Technology < g.hearn@ qut.edu.au > \\ Megan Kimber \\ Queensland University of Technology < $\underline{\text { m.kimber@qut.edu.au }}>$ \\ June Lennie \\ Queensland University of Technology < j.lennie@qut.edu.au > \\ Lyn Simpson \\ Queensland University of Technology < le.simpson@qut.edu.au $>$
}

\begin{abstract}
From the participatory action research we have conducted in two rural communities in Australia we suggest six factors that assist in achieving sustainability for ICT initiatives undertaken in pursuit of regional development. They include:

- Clearly specified sustainability goals;

- Leveraging micro-business enterprise development off government funded technical and human infrastructure provision, and using local industry strengths;

- Learning from global experiences whilst building on local assets;

- Finding innovative business models to capitalise on new opportunities for content and applications;

- Ensuring community involvement in deciding, planning and evaluating projects; and

- Adopting a learning approach.
\end{abstract}

\section{Introduction}

Information and Communication Technologies (ICTs) are often promoted as central to reviving and sustaining regional communities (eg. Simpson and Hunter, 2001). This focus is particularly important in Australia, which is geographically dispersed and has many such communities. Periodic and ongoing drought and the shifts in the global economy away from the goods and services produced in these communities appear to have weakened them. Despite the emphasis placed on ICTs, it seems that many initiatives have stalled. In short, the question of how community-based ICT initiatives "can survive financially, that is be 'sustainable' in the longer term" has grown in significance (Gurstein, 2001, p. 279).

\footnotetext{
${ }^{1}$ A version of this article was first presented at the CIRN conference held in Prato, Italy in 2004. The research for this project is funded by the Australian Research Council; and the Commonwealth Department of Family and Community Services, Queensland Department of Natural Resources, Mines and Energy, Office of Women in the Queensland Department of Local Government, Learning Network Queensland, and Legal Aid Queensland. We wish to thank Kitty van Vuuren and Emma Kennedy da Silva for their research assistance.
} 
In this article we initially consider the role of ICTs in sustainability of regional communities and then explore some of the reasons for the failure of ICT initiatives. ${ }^{2}$ This discussion leads us to ask whether there are more effective models of the implementation of ICTs and their role in regional development. Based on our review of the literature in this field and participatory action research conducted in two regional communities in Queensland we propose regional ICT initiatives need to:

- $\quad$ achieve clarity in specifying sustainability goals;

- leverage micro-business enterprise development off government funded technical and human infrastructure provision;

- $\quad$ build on local industry strengths; to learn from global experiences whilst building on local assets;

- find innovative business models to capitalise on new opportunities for content and applications;

- $\quad$ ensure community involvement in deciding, planning and evaluating projects; and

- $\quad$ adopt a learning approach through cycles of evaluation based on action research.

\section{The role of ICTs in sustainability in regional communities}

The position that ICTs have a role in enhancing 'sustainability' in regional communities has several threads and can be seen from three spheres - community, government and business. Here, 'community' is understood as sustainability what a group of people living in a geographically defined area consider important, how they want to achieve those goals and what they judge their success by (Simpson and Hunter, 2001; RIRDC, 2000; Stellar, 2002; Gurstein, 2001) ${ }^{3}$. Representatives of each sphere sometimes ascribe different meanings to sustainability. Briefly, from a community perspective, sustainable ICT projects are those that can pay their own way, generally without reliance on government funding. They serve individual and community needs, are easily accessible and promote the social, cultural and/or economic development of the community (eg. build social capital and assist local business). Those who adopt a business perspective view sustainability in terms of whether the project is commercially viable and profitable. Proponents of the government perspective focus on service provision. They recognise that

\footnotetext{
${ }^{2}$ In this article the term, community, is used in preference to civil society because it better captures the idea of a group of people who live in a geographically defined area and interact with each other to achieve shared social, cultural, environmental and economic goals (Stellar, 2002). In this instance a 'regional community' is a community that is located in a non-metropolitan area (Simpson and Hunter, 2001, p. 5). For the purpose of this article we adopt the understanding of regional used by Simpson and Hunter (2001, p. 5). Like the Australian Bureau of Statistics, they refer to 'regional' as the locations that are considered 'non metropolitan' - that is outside capital cities. We would add that the size and diversity of Australia means that there can be significant differences between communities in terms of population size and socioeconomic profile and economic situation. However, it does appear that people in regional areas generally have lower incomes and educational levels than those in capital cities. Simpson and Hunter also point out that it is those communities that have relied on agriculture and mining that have suffered most from the shift to knowledge economy.

${ }^{3}$ Here, sustainability in relation to ICT might be seen at three, continuous and overlapping levels. First is that of the specific ICT project (Department of Communications, Information Technology and the Arts [DCITA], 2003; Gurstein, 2001; Thompson, 2002). Second is that of the organisation (Krouk, Pitkin and Richman, 2000; Fortier, 2000; Kermode, 2002). One example is hose that aim to use ICT to meet non-ICT ends like community development (Krouk, Pitkin and Richman, 2000; Fortier, 2000; Kermode, 2002). Third is that of the community - what a group of people living in a geographically defined area consider important, how they want to achieve those goals and what they judge their success by (Simpson and Hunter, 2001; RIRDC, 2000; Stellar, 2002; Gurstein, 2001).
} 
governments have Community Service Obligations and that market failure occurs, especially in rural, regional and remote areas where the costs of setting up and maintaining ICT services can be very high. These factors make government support of ICT initiatives necessary. Yet these advocates acknowledge that, in the current policy context, government funds are limited. Consequently, greater financial responsibilities are being foisted onto local communities (Alston, 2002).

Expanding on the community perspective, Gurstein (2001) argues that if an ICT:

"...facility is seen as providing [a] community service then the ongoing sustainability can be understood within the context of the ongoing sustainability of other community services such as schools, health facilities and so on and can be drawn from whatever sources (taxes, grants in aid and so on) are supporting those services.

However, if the facility is seen as only providing a service to specific individual users, then the model of sustainability must necessarily be one of identifying individual revenue sources (fees for service) and immediately puts the facility into the context of market-driven mechanisms.

If ... this facility is a necessary component of capacity development for local citizenship, that is of maintaining a local empowerment, then clearly we must look at the issue of sustainability in the first context. The aim of the research then becomes identifying the manner in which the facility can become sufficiently and visibly embedded in the community so that it is recognised for what it is, a necessary component for community survival. Doing this, of course, requires the development of strategies and applications which link the facility directly into other and necessary community processes and involves determining how to use the technology as the basis for more effective and efficient organizational management."

(pp. 279-80)

What Gurstein makes clear is that not only does sustainability mean different things to different groups but also that these understandings can derive from the purpose from which the facility is seen to be used and from the ideological position(s) of those users.

Turning to Australia, a significant literature exists documenting the way in which climatic conditions, corrupt world markets, low commodity prices and agricultural restructuring have resulted in a diminished Australian rural and regional economy (Smailes, 1997; Tonts, 2000; Gray and Lawrence, 2001). While this situation has culminated in governments implementing a range of policy initiatives directed at regional revitalisation, one group of government-funded strategies has focused on new communication and information technologies. These schemes include the $\$ 464$ million worth of projects that have been funded through the Commonwealth Government's Regional Telecommunications Infrastructure Fund, Networking the Nation, since it was first established in 1997.

What has been presumed in the allocating of funding for these ICT initiatives is that they will provide the key to rural and regional development. This assumption is clearly articulated in the Commonwealth Government's policy framework for new technologies:

"The information economy will play a seminal role in the growth of regional and rural Australia. Online services can build stronger and more viable regional communities, with enhanced investment, employment and skills, by providing better access for businesses to markets and market information, and enabling more efficient marketing and distribution of products and services" (National Office of the Information Economy, 1998, p. 3).

This position is also evident in the policy pronouncements of rural industry. In a number of reports the Rural Industries Research and Development Corporation has suggested that non-metropolitan Australians will benefit economically from new technologies as these will provide new employment opportunities, the 
potential to buy and sell online, an increase in services and access to education and training (Da Rin and Groves, 1999; Groves and Da Rin, 1999a, 1999b).

Within this context the Commonwealth Department of Communication, Information Technology and the Arts (DCITA, 2003) released a discussion article relating to the viability of Online Access Centres (OACs) in regional Australia. OACs are described as: "centres with full or part-time staff, unstaffed Internet kiosks, computers in public libraries with Internet access and those rural transaction centres that provide communities with Internet access." They offer people on low incomes affordable access to, and training in, ICTs and provide a range of communications, computer, resource, education and training, government, social development and community development services (DCITA, 2003).

DCITA's document illustrates that, in Australia, governments are instrumental in driving ICT projects through various funding initiatives. At the Commonwealth level one of the most well-known programs is Networking the Nation $(\mathrm{NTN})^{4}$. State/Territory government commitments include: the Community Technology Centres Program (New South Wales); Communities Online (Tasmania), Connecting Victoria Connecting Communities (Victoria); and Online Public Access in Libraries (Queensland). Local governments support online public access centres by providing rent and maintenance, and by acting as OAC facilitators and managers. Yet, with current government programs like NTN winding down, the continuing feasibility of these projects requires local communities to find ways to make them self-sufficient and economically viable (DCITA, 2003, pp. 3, 10). The question becomes, then, why have ICT initiatives have often failed in regional communities and what can be learnt from successful models to better assist communities to achieve a sustainable ICT project?

\section{A critique: reasons for the failure of ICT initiatives in regional communities}

Based on several analyses, it could be suggested that a variety of factors contribute to the stalling of ICT projects in regional areas. These factors are that many initiatives are largely ICT supply-driven and fail to specify and address local and cultural impediments and opportunities, they do not take account of the dynamics of the global ICT industry, they are overoptimistic about the productivity improvements that ICTs can bring in traditional industries; and they often overlook the importance of content per se. They are discussed briefly below

\section{ICT supply-driven initiatives and failure to specify and address local and cultural impediments and opportunities}

As many initiatives are largely ICT supply-driven, they result in inadequate consideration being given to the local context (Simpson and Hunter, 2001; DCITA, 2003, pp. 3-10) ${ }^{5}$. Local cultural impediments and opportunities can be overlooked as a result (Oakley and Campbell, 2002). Examples include: the length of time the community has been exposed to ICTs; community members' access to and experience with these technologies; the type of industry(ies) in, and the socio-economic structure of, the area; and how businesses view the use of ICTs in relation to their operations ${ }^{6}$.

\footnotetext{
${ }^{4}$ Other programs include the Telecommunications Action Plan for Remote Indigenous Communities, Rural Transaction Centres, and the Family and Community Network Initiative.

${ }^{5}$ Telecentres in the United Kingdom and Europe might provide one example. They were established on a supply-side basis, with the private sector being seen as the main service provider. As only $25 \%$ of United Kingdom telecentres were profitable and 30\% experienced losses (DCITA, 2003, pp. 3-10), it appears that the possibility of market failure was not considered.

${ }^{6}$ For example, a community in which there has been population decline and that has had limited exposure to ICTs is quite likely to not have a significant number of technologically literate citizens (Fortier, 2000; Simpson and Hunter, 2001). A community that has relied upon agriculture and whose members lack
} 
By overlooking such contextual considerations, the advocates of ICT projects can mis-specify and under resource the social and human infrastructure required. It is necessary that citizens are able to not only access that technology but that they also possess the skills to use and the resources to access them. This endeavour might require governments and communities employing skilled specialists in regional areas (Simpson and Hunter, 2001). As a number of Australian and international initiatives have indicated, relying on volunteers to raise awareness and to provide training can be detrimental to the sustainability of a project in that, where there is only a small pool of volunteers to draw upon, these people may suffer from burnout (Simpson and Hunter, 2001; Colle, 2000).

\section{Initiatives that do not take account of the dynamics of the global ICT industry}

Outcomes like those considered above highlight the digital divide. The digital divide - referring to those who lack the ability or the capacity (including affordability, information literacy skills and location) to access and use basic ICT services - exists between and among developed and developing countries, between rural and urban areas, within urban areas, between racial and ethnic groups, and between those society considers able and those it deems disabled (Rooksby, Weckert and Lucas, 2003). These points regarding the nature of the digital divide are reinforced by the uptake of ICTs being slower in those regional areas where incomes (and educational levels) are lower than in some urban areas. As ICT uptake has been identified as related to gender, age, education, income and interest level (Simpson and Hunter, 2001, pp. 5-9; Rooksby, et al., 2003; The Rural Women and ICTs Research Team, 1999), then it may also be a socio-economic divide. Thus supply-side policies could be insufficient to address it adequately (Simpson and Hunter, 2001, p. 10; Rooksby, et al., 2003).

The digital divide has exacerbated existing socio-economic disparities (Krouk, Pitkin and Richmans, 2000; Rooksby, et al., 2003) by further marginalizing those who are already disadvantaged while extending the power and reach of groups such as those who are information literate or who own and manage capital (Gurstein, 2001). Where ICTs are considered a driving force behind globalisation, it is possible that "globalisation hollows out local communities .... [making] whole regions ... expendable in relation to these overwhelming global forces" (Gurstein, 2001, p. 264). By considering the digital divide it is evident those who have been implementing some ICT projects in regional communities might have been ignoring the local context and been giving insufficient attention to the structure of the global ICT industry. Some approaches might provide access to "another tool of information, without questioning its forms and content," thus consolidating "social and inequalities" (Fortier, 2000, p. 452) as a consequence".

\section{Overoptimism about the productivity improvements that ICTs can bring to traditional industries and overlooking the importance of content per se.}

Another reason why some ICT projects fail is that their drivers can be overoptimistic about the productivity improvement ICTs can bring in traditional industries. This enthusiasm might lead governments and communities to focus on traditional industries rather than to foster diversification such as through the development of new industries. This situation can contribute to people neglecting innovative and creative content that is relevant to the needs of a local community. ICTs "are changing the way all sectors operate

adequate health facilities may not consider a web portal relevant to its needs (Fortier, 2000; Cole, 2001). In a community in which businesses are focused on survival then ICT uptake can be slow (Simpson and Hunter, 2001, pp. iv, 13-38).

${ }^{7}$ For example, Fortier (2000, p. 451) suggests that, as 'multipurpose community telecentres' were generally located in town centres, they were not likely to reach the 'most disadvantaged' who often lack literacy skills and are unable to afford basic ICT training. It appears that such an approach might provide access to 'another tool of information, without questioning its forms and content', thus consolidating 'social and inequalities' (Fortier, 2000, p. 452). If this is the case, governments need to assist in improving access to information about ICT, affordable information literacy and affordable ICT services (Rooksby, et al., 2003). 
...." (Hearn and Manderville, 2004) ${ }^{8}$. Yet research indicates that productivity growth arises from a complex set of factors, not just ICTs (Castells, 1996a, 1996b; Cogburn, 1998; Engelbrecht, 1997; Gretton, Galia and Parham, 2003; Hearn and Manderville, 2004; The Economist, 1999).

In general, over several decades, productivity growth has not paralleled investment in ICTs (Castells, 1996a, 1996b; Hearn and Manderville, 2004). As an analysis of Australia's productivity upsurge (approximately 3.2\% per annum) during the 1990s reveals, the link between ICTs and productivity growth is complex and might not be even across all firms and industry sectors. A set of multiple and interacting factors might have been responsible for the productivity gains that Australia experienced. One of these was the catch-up phenomenon. This characteristic is evident in Australia's productivity surge pre-dating that in the United States. The greater access to, and better use of, ICTs in many industry sectors in Australia was facilitated by the policy reforms introduced progressively from the early 1980s. These reforms were aided by organizational restructuring, and by the up-skilling of workers and managers (Gretton, et al., 2003; Parham, 2003; Parham, 2002) ${ }^{9}$.

The multiplicity of factors in the productivity/ICT equation is apparent when examining specific cases. These examples indicate that there is "significant variation in mechanisms of how ICTs might yield productivity gains" (Hearn and Manderville, 1994, p. 2). The use of ICTs within an enterprise could either enhance or reduce productivity through their effect on at least five functions and processes.

First, they might reduce the informational component of an enterprise's transaction $\operatorname{costs}^{10}$. Alternatively, ICTs may increase transaction costs by adding additional steps in the production process through increases in the level of technology and/or staff needed to process logistical information. ICTs might also expand the amount of information that has to be collected ${ }^{11}$. There are also significant hidden human resource costs in terms training and recruitment (Hearn and Manderville, 2004, pp. 3-4).

Second, distributed systems, intranets and web band services all change the logic of space and time that connects enterprises to their stakeholders. However, the opposite is also true. For example, where banks have replaced branches with ATMS in regional Australia their managers appear to have failed to understand their customers' attachment "to real rather than virtual branches" (Hearn and Manderville, 2004, p. 4). New markets and users can clearly be reached.

Third, adding information to an existing product or service can make it 'smarter' and more attractive to clients. ICTs are used widely in agriculture, for instance (Hearn and Manderville, 2004, p. 5; Goggin 2000). Yet increased information intensity can add significant costs to an enterprise without improving quality or lowering cost. Higher transaction costs that have derived from collecting and analysing information in order to generate "quality assurance, improved decision making, or simply the fact that ICTs make information collection possible" (Hearn and Manderville, 2004, p. 5).

8 "... there is a good deal of "boosterism" in discussions about ICTs and productivity and a common argument is that ICTs are important enabling technologies that generate productivity gains across sectors' (Hearn and Manderville, 2004).

${ }^{9}$ Since the mid-1980s, Australian investment in ICTs has grown strongly. In the 1990s, investment in hardware grew by $35 \%$ per year and investment in software by $20 \%$ a year (Parham, 2002, p. 8).

${ }^{10}$ ICT use may improve the handling of information by eliminating logistical steps in the supply chain, reducing multiple handling of information, making information easier to find, or speeding up the transfer of information. These improvements might also involve the elimination of labour and thus the associated costs.

${ }^{11}$ A key factor in this situation derives from the externalities of ICTs we have already referred to. The need for an informational connection to others, or to conform to the standards of an industry, can drive greater information collection and transmission (Hearn and Manderville, 2004, pp. 3-4). 
Fourth, "ICTs have engendered completely new products and services in the form of digital content and applications" (Hearn and Manderville, 2004, p. 6). New businesses that provide web mail services (eg. Growzone - http://www.growzone.com.au) and the development of community portals in various regional and rural areas provide two examples (eg. http://www.elaunceston.com/; Jenkins, 2000; http://www.gladstone-online.com.au/index.htm; Thompson, 2002) ${ }^{12}$. Another example is Elders (http://www.elders.com.au/), which uses the Internet to provide farmers with online services in relation to livestock sales and prices, breeding, grain, wool and other such services. It also has links to Australian and international rural and farming sites.

Finally, the use of ICTs might sometimes be related to their symbolic value. They carry connotations of power and supremacy. Yet, as automated voice systems and call centres indicate, the use of ICTs can also be received negatively (Hearn and Manderville, 2004, p. 6). For example, in two Australian federal government agencies that provide assistance to the unemployed (and underemployed) and to children, the introduction of a heavy reliance on call centre culture and investment in related IT in the early 2000s has decreased corporate health and generated adverse publicity about client outcomes" (p. 6).

We argue that the equation that ICTs equals productivity is misleading. Thus the claim that ICTs equal regional sustainability is also wrong. Careful specification of a number of factors are required if one is to understand the impact of ICTs on regional sustainability. Moreover, these characteristics can change at the level of the individual enterprise, either helping or hindering sustainability in particular cases. In the final section we report on case study work in two rural communities directed towards evaluating the sustainability of community ICT projects as a preliminary step towards the identification of these key factors.

\section{The way forward: lessons from participatory action research in Queensland, Australia}

The key aim of the LEARNERS ${ }^{-}$Learning, Evaluation, Action and Reflection for New Technologies and Rural Sustainability - project was to assist in "empowering diverse community members in [learning and] evaluating community development initiatives that use new communication technologies" to achieve social and economic benefits (Lennie, Simpson and Hearn, 2003, p. 1). We adopted a "whole of community' approach, concentrating on building learning communities and recognising new, more empowering forms of leadership that might be expected to help sustain rural communities (p. 1). We focused on the human and social infrastructure rather than the technical infrastructure. Using participatory action research we sought to involve a diversity of community members and the industry partners affected by the initiatives that community members chose (see Figure 1). This deliberate strategy was to ensure that the initiatives were relevant to the communities so that their knowledge and skills were increased, and to incorporate local knowledge and ideas, and to enhance empowerment. The two communities and the industry partners participated actively in continuous and overlapping cycles of planning, acting, observing, and reflecting through meetings, workshops, focus groups, interviews, teleconferences and e-mail discussion lists. Changes were made in response to participant feedback (Lennie, Hearn, Simpson, van Vuuren and Kennedy, 2003, p. 6).

Alpha Shire is located in an area built around farming. When the project commenced it had a population of approximately 3,800 , had poor communication systems and a lack of services. It was considered to be disadvantaged. Beta Shire is located in an agriculture, farming and tourism area. When our

12 eLaunceston was initiated by the telecommunications corporation, Telstra, in conjunction with key stakeholders (including the council, local businesses and government departments) and through extensive consultation with the local community. It covers tourism, news, weather and links to local businesses. eLaunceston promotes tourism and businesses in the region and provides local community members with the ability to engage at local and international levels. 
study began, its population was 10,400 and declining. Although this Shire had good communication systems, public Internet access was poor and there was a lack of awareness among some sections of the business community of the opportunities that new ICTs could provide.

Alpha implemented a range of community and economic development projects prior to the commencement of our research project. Initiatives involving the use of ICTs included:

- The Shire website sponsored by the Council.

- Public Internet access at the library.

- A Learning Network Centre that provides access to a range of ICTs and offers support for students undertaking external studies.

- Videoconferencing facilities that enable access to legal advice and information.

- Computer and Internet training courses and support services.

- A Cyberflora project that involved development of a website and email network to facilitate the creation of a mural in the botanical gardens.

- A school website.

- After hours access to computers and the Internet to adults provided by the school.

- The school children taught adults how to use computers and the Internet.

- An online magazine for young people had been created.

In Beta, the Council and the local business community undertook key ICT initiatives to enhance the Shire's economic development prospects. They include a virtual community project aimed at enhancing telecommunications and e-commerce access in the region and a community Learning Centre. The first project was initially funded through the Council securing a grant from the federal government's Networking the Nation program.

In both communities, women took key leadership roles in ICT initiatives and the majority of project participants were women. Other research identifies women as 'new pioneers' in the adoption and use of ICTs in rural and regional Queensland (The Rural Women and ICTs Research Team, 1999). It could be speculated that women's participation in these initiatives could be related to their roles within government, non-profit organisations, business and the community more generally. It appears that women's involvement in ICT projects could be vital to the ongoing sustainability and success of those initiatives.

A number of other insights about the sustainability of regional ICT projects can be gained from these cases. In feedback on the initiatives, participants in both communities understood sustainability as community sustainability. They stressed the growing import of financial viability in a time of diminishing government assistance. Yet perhaps more significant than, and a precursor to, this financial viability is the requirement that the ICT initiative is relevant to the community. As one participant stated, sustainability means that the "project is ongoing and can sustain itself financially and continue to provide a service to the community". Another participant argued that the initiative "must be of benefit to the community and continually grow and change with the community. To meet the shifting needs of individuals and groups they must be relevant and useful". The project needs to "not only [be] able to keep itself going but to be a growing entity" as well.

From this perspective, local needs and interests must be addressed and the community's sustainability goals must be clear. It can be extrapolated that success in attaining these goals necessitates the community having effective opportunities to be involved in deciding on the project(s) to be pursued and in evaluating it. Therefore, it is essential the community 'owns' the initiative.

These sentiments imply, as a participant put it, "if you want your project to be in place for a long time you need to build some kind of sustainability into it." For another participant, you need "a good plan [first] and checkpoints along the way." This planning and these checkpoints contributed to participants' assessment that the LEARNERS process had assisted them to identify strategies for achieving sustainable outcomes, including the potential for reducing reliance on government and empowering the local community. In most cases, community members learned new planning and evaluation skills and techniques that were relevant to their needs. 
As indicated earlier, this study assisted two communities to identify the ICT projects they wanted to evaluate in order to better meet community needs. It entailed drawing on local knowledge and content. The involvement of key community members enabled available knowledge and learning resources to be utilised effectively, and relevant skills and knowledge to eventually be diffused to others the community. Drawing on the experiences of other communities whilst remaining attuned to local needs and interests helped stakeholders to identify ways in which their projects could become more sustainable and successful. Participants also valued the opportunity to network with people in other organisations and communities ${ }^{13}$.

These findings indicate that learning strategies for rural and regional communities need to be planned and that communities need to be helped to help themselves. The "strengths and resources of the community" should be identified and be used effectively "to advance the community". As another participant put it, "you need to get people involved and you need to get word out that you need people to work on this and mention what you"re trying to do. But I think it needs to be done in a practical sort of way".

From our experience, 'being practical' means engaging local leadership, developing useful skills and providing information in ways appropriate to rural and regional people. Several participants stressed the significance of ongoing local leadership and planning for human resource requirements such as trained staff, especially where they could play a role in changing people's attitudes towards technology. "People think that the Internet is for young people and don't see the benefits it could have for them. We need to educate people to overcome this attitude and this is difficult without a dedicated IT person in the Shire." Where communities have had limited exposure and/or access to appropriate technologies this situation might present a significant barrier to attaining sustainability goals when government services and/or funding is withdrawn. The participants who expressed this opinion strongly had experienced detrimental effects from the Council's decision to withdraw the local ICT support person.

\section{Other key factors in ICT sustainability}

An implication of these governmental actions means that using local content and applications, and the deployment of innovative and/or creative business strategies, were identified as a crucial but underdeveloped source in both communities. Focusing on local content and applications the community radio network, BRACS (http://www.teabba.com.au), in the Northern Territory provides one example. Others include Telstra's eLaunceston project (Jenkins, 2000), the Mainstreet portal in Western Australia (Thompson, 2002) and successful telecentres in Canada, India, Australia and the United States (Colle, 2000). Examples of innovative/creative business strategies include initiatives undertaken by the Maffra Area International Inc (Kermode, 2000) in Gippsland, Australia; Australian Internet publishing business, On the Stone (http://www.onthestone.com.au); Telstra's eLaunceston project (Jenkins, 2000); several telecentres and telework projects; and several Australian businesses like WindSong Records and Kangaroo Pacific Trading (Colle, 2000; Simpson and Hunter, 2001).

Gurstein (2001, p. 271) notes that organisations can use ICTs to assist local development in a number of ways. First, they can "enable local residents to do the activities they have always done better, faster, more cheaply or more efficiently, thus maintaining their competitive position in the large economy." However, cost-effectiveness is rarely achieved for reasons such as those discussed earlier. Gurstein's second and third points are more promising. ICTs can be used as a "resource for new social and commercial enterprises, new styles of development and new initiatives, doing things at the local level which have not been done before as a base for local economic advance." Finally, they can be used as a "means to link into larger networks where the local economic activity might not be sustainable and effective when undertaken in a fragmented or piecemeal way."

\footnotetext{
${ }^{13}$ Networking was a feature of several other projects examined for this research (Colle, 2000; Simpson and Hunter, 2001).
} 
As Simpson and Hunter (2001, p. 38) argue, it is essential that a community identifies its strengths and weaknesses. This is about being aware of what the region has to offer and the potential that might exist for 'exploiting' it. Yet "identifying the complex range of factors that go to making a successful business case for the path the community takes time and investigation of the possibilities" (p. 38). Simpson and Hunter's (2001, pp. 38-9) evidence suggests that some of the businesses that achieved success through NTN funding used the Internet to: reduce transaction input costs; speed up and improve information transfer; and aggregate suppliers. In these cases the Internet was seen as "a tool" or "building block for economic growth and social \& regional development. ... A community needs to ensure that it clearly knows why it needs and how it will utilise online services to create employment, enhance ICT skills and improve the lives of its members' before it examined what telecommunications services it required (p. 39). Thus, "like any good business plan, a community needs to look at what its realistic goals are and what is required to reach them" (p. 39).

Our research suggests that sustainability requires engaging community leaders and volunteers (Simpson and Hunter, 2001, p. 38; Colle, 2000; Jenkins, 2000). However, it is necessary to guard against volunteer burnout - a situation that can be compounded in regional areas that have small populations - and be vigilant in protecting leadership positions from being “... 'hijacked' by well meaning people who lack the required vision and drive" (Ipen in Simpson and Hunter 2001, p. 20).

Adequate resourcing from sources like networking and partnerships with other key stakeholders including business, government, educational institutions and the non-profit sector is necessary here. Yet such partnerships can take a long time to develop and do involve some alignment with the aims and priorities of these stakeholders. As much as business needs to see that the use of ICTs will provide them with desired benefits it is necessary to find a "fit with government policies and procedures" (Simpson and Hunter, 2001, p. 39; Also see http://www.teabba.com.au; Colle, 2000; Jenkins, 2000)

Employing skilled people such as an ICT specialist, business manager and/or project officer can help to minimise burnout and to make these assessments (see Simpson and Hunter, 2001, http://www.teabba.com.au). In this sense regional communities need to combine top-down and bottom-up approaches (Colle, 2000) to leverage initiatives off government funded technical and human infrastructure provision, and to build on local industry strengths. In relation to local industry, leveraging can assisted by finding and using innovative and/or creative business models to capitalise on new opportunities for content and applications (Jenkins, 2000; Colle, 2000; Simpson and Hunter, 2001; http://www.on.the.stone.com.au).

Finally, regional communities need to be aware that things can go wrong and momentum lost as a result (Simpson and Hunter, 2001, p. 39). Thus it is essential for them to adopt a learning approach like that which occurs through using cycles of evaluation based on an action research framework (Lennie and Hearn, 2003; Jenkins, 2000, pp. 24-7). This method enables the development of a plan that incorporates contingency strategies (Simpson and Hunter, 2001, p. 39) and ensures the incorporation of clear assessment and evaluation techniques that take diverse community, government and business agendas and needs into account.

\section{Conclusion}

Our research, combined with several other Australian and international studies, suggests that there are several factors that can assist in the sustainability of ICT projects, and can promote economic and community development They cover ensuring the community's sustainability goals are specified clearly through measures including community involvement in deciding, planning and evaluating projects; and adopting a learning approach through cycles of evaluation based on action research. These features also include leveraging micro-business enterprise development off government-funded technical and human infrastructure provision, building on local industry strengths, learning from global experiences whilst building on local assets; and finding innovative business models to capitalise on new opportunities for content and applications. 
These characteristics were evident in successful Australian and international initiatives. They were missing from projects that stalled, especially through their drivers' failure to consider the local context and the dynamics of the global ICT industry. In ignoring these features, the strengths and impediments unique to a particular community were sometimes overlooked and the assumption that the use of ICTs translates into greater productivity was not questioned.

Figure 1: The LEARNERS Process

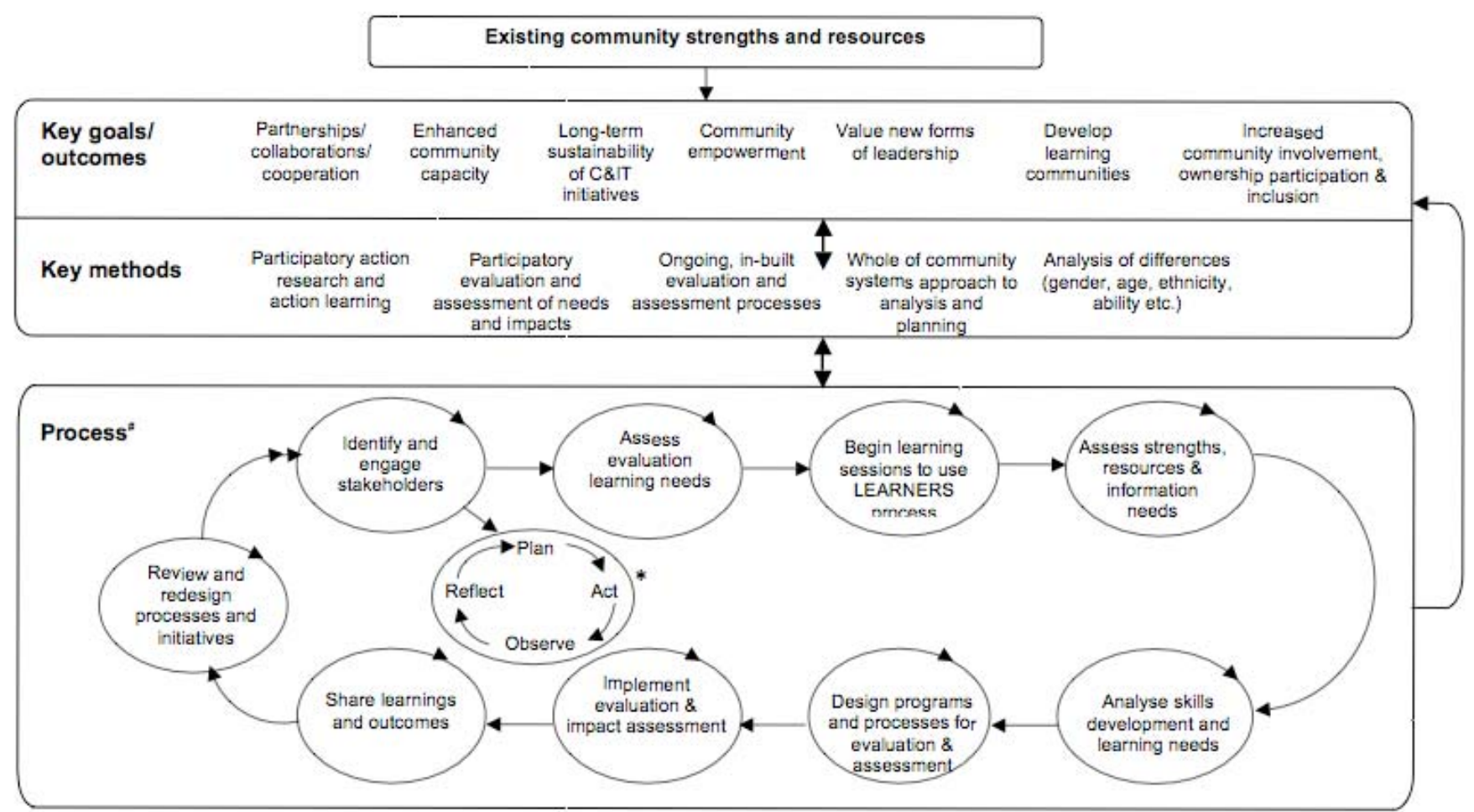

\# All of these steps do not have to be followed and do not have to be undertaken in this sequence. They represent activities that could potentially be undertaken by stakeholders and participants.

- Each of the steps involves a cycle of planning, acting, observing and reflecting 


\section{References}

Alston, M. (2002). “Social Capital in Rural Australia”. Rural Society, 12 (2), p. 93-104.

Arthur, W. B. (1996). "Increasing Returns and the New World of Business". Harvard Business Review, pp. 100-109.

Castells, M. (1996a). "Megacities and the End of Urban Civilisation”. New Perspectives Quarterly, Summer, 13 (3), p. 12.

Castells, M. (1996b). The rise of the network society. Blackwell Publishers, Cambridge, p. MA.

Cogburn, D. (1998). Globalisation, Knowledge, Education and Training in the Information Age. Accessed from: http://www.unesco.org/webworld/infoethics_2

Colle, R. D. (2000). Telecentres as vehicles for community informatics in C. Romm, W. Taylor and C. Scott (Eds), Get Smart Conference, 14-15 December 2000. Central Queensland University: Rockhampton, Queensland.

Da Rin, J. and J. Groves (1999). Demand and supply of Internet content for Australian farm businesses. Rural Industries Research and Development Corporation, p. Canberra.

Department of Communications, Information Technology and the Arts (DCITA) (2003). Maintaining the Viability of Online Access Centres in Regional, Rural and Remote Australia, discussion article. Accessed 24 November 2003 from: www.dcita.gov.au/Article/0,0_2-1_1-2_5-4_117050,50.html

eLaunceston (n.d). Accessed 19 July 2004 from: http://www.elaunceston.

Elders (n.d.). Accessed 19 July 2004 from: http: //www.elders.com.au

Engelbrecht, H. J. (1997). "The international economy: Knowledge flows and information activities. The new research frontiers of communication policy" in D. Lamberton (Ed) The new research frontiers of communication policy. Elsevier: Amsterdam.

Fortier F. (2000). "Virtual Communities, Real Struggles: Seeking Alternatives for Democratic Networking" in M. Gurstein (Ed) Community Informatics: Enabling Communities with Information and Communication Technologies. Idea Group Publishing: Hershey and London.

Gladstone Online (n.d.). Accessed 19 July 2004 from: http://www.gladstone.com.au

Goggin, G. (2003). Rural Communities Online: Networking to link Consumers to Providers. A research project commissioned by the Telstra Consumer Consultative Council. Centre for Critical and Cultural Studies, University of Queensland, Brisbane, February 2003.

Gray, I. and G. Lawrence (2001). A Future for Regional Australia. Cambridge University Press, Cambridge.

Gretton, P., Galia, J. and Parham, D. (2003). The Effects of ICTs and complementary innovations on Australian productivity growth, Productivity Commission: Canberra, July.

Groves, J. and J. Da Rin (1999a). Buying and selling online: The opportunities for electronic commerce for Australian farm businesses. Rural Industries Research and Development Corporation: Canberra.

Groves, J. and J. Da Rin (1999b). Economic and social impacts of farm Internet use, Rural Industries Research and Development Corporation, Canberra. 
Growzone (n.d.) Accessed 19 July 2004 from: http://www.growzone.com.au

Gurstein, M. (2001). “Community Informatics, Community Networks and Strategies for Flexible Networking" in L. Keeble and B. Loader (Eds) Community Informatics: Shaping Computermediated Social Relations. Routledge: London.

Harding, A. and S. Richardson (1998). Unemployment and Income Distribution. Discussion article Number 32. National Centre for Economic Modelling. Canberra Accessed 28 April 2004 from: http//: www.rba.gov.au/PublicationsAndResearch/Conferences/1998/hardingRichardson.pdf (.also available at: http: www.natsem.Canberra.edu.au/pubs/dps/dpp32.pdf).

Hearn G. and T. Manderville (2004). How to be productive in the knowledge economy: The case of ICTs. unpublished article.

Jenkins, A. (2000). eLaunceston: a Telstra Research Project, in C. Romm, W. Taylor and C. Scott (Eds), Get Smart Conference, 14-15 December 2000, Central Queensland University: Rockhampton, Queensland.

Kermode, F. (2002). Experiences of a Community Group in Gippsland, Conference Proceedings, Electronic Networking 2002 - Building Community, July 3-5.

Krouk, D., B. Pitkin and N. Richman (2000). "Internet-based Neighbourhood Information Systems: A comparative Analysis" in M. Gurstein (Ed) Community Informatics: Enabling Communities with Information and Communication Technologies. Idea Group Publishing: Hershey and London.

Lennie, J., and G. Hearn (2003). The potential of PAR and participatory evaluation for increasing the sustainability and success of community development initiatives using new communication technologies. Proceedings, Action Learning, Action Research \& Process Management and Participatory Action Research Congress, University of Pretoria, South Africa, 21-24 September, 2003. Available from: http://www.education.up.ac.za/alarpm/PRP pdf/Lenny\&Hearn.PDF)

Lennie, J. G. Hearn, L. Simpson, K. van Vuuren and E. Kennedy (2003). Interim report on the LEARNERS project, Service Leadership and Innovation Research Program and Creative Industries Research and Applications Centre, Queensland University of Technology: Brisbane.

Lennie, J., G. Hearn and L. Simpson (2002). Can the participatory evaluation of new communication technology initiatives assist in building sustainable and inclusive rural communities? Australasian Evaluation Society International Evaluation Conference, Wollongong, New South Wales, 30 October - 1 November 2002. Available from: http://www.aes.asn.au/conference/cfindex.htm

Loges, W. E. and J. Y. Jung (2001). "Exploring the digital divide”. Communication Research, 28(4), pp. 536-562.

Martin, H. P. and H. Schumann (1996). The global trap. Pluto Press: Australia

Oakley, K. and T. Campbell (2002). On the move: A look at the social uses of mobile and wireless communications. The Local Futures Group, London.

On the Stone: The Community Publishers (n.d.). Accessed 16 May 2004 from: http://www.onthestone.com.au

Parham, D. (2003). Australia's 1990s Productivity Surge and its Determinants Revised Draft of a Article presented to the $13^{\text {th }}$ Annual East Asian Seminar on Economics, Melbourne, 20-22 June 2002, Revised Draft, May. 
Rooksby, E., J. Weckert and R. Lucas (2003). “The Rural Digital Divide”. Rural Society, 12 (3), pp. 197210.

Shapiro, C. and H. R. Varian (1999). Information Rules: A Strategic Guide to the Network Economy. Harvard Business School Press: Boston.

Shields, P. and R. Samarajiva, R. (1993). "Competing frameworks for research on informationcommunication technologies and society: toward a synthesis". Communication Yearbook, 16, pp. $349-80$.

Simpson, R. and A. Hunter (2001). The Internet \& Regional Australia: How rural communities can address the impact of the Internet. Rural Industries Research \& Development Corporation: Canberra.

Smailes, P. J. (1997). "Socio-economic change and rural morale in South Australia 1982-1993", Journal of Rural Studies, 13 (1), pp.19-42.

Stellar, G. (2002). Community, Content, Collaboration and Courage!, Keynote Address to the Electronic Networking 2002 - Building Community Conference, Monash University, Melbourne, 3-5 July.

Top End Aboriginal Bush Broadcasting Association (TEABBA) (n.d.). Accessed 16 May 2004 from: http://www.teabba.com.au

Thompson, H. (2002). Creating and Sustaining Online Communities-Replicable web-based Services Meeting the Diverse Needs of Regional and Rural Australia, Article Presented to the Learning Cities and Regions Conference, Melbourne, October 14-15.

Tonts M. (2000). "The Restructuring of Australia's Rural Communities" in B. Pritchard et al (Eds) Land of Discontent. University of New South Wales Press: Sydney.

The Economist (1999). “The New Economy: Work in Progress", The Economist, July 24, pp. 19-22.

The National Office for the Information Economy (1998). A Strategic Framework for the Information Economy. Australian Government Publishing Service: Canberra.

The Rural Women and ICTs Research Team (1999). The New Pioneers: Women in rural Queensland collaboratively exploring the potential of communication and information technologies for personal, business and community development. The Communication Centre, Queensland University of Technology: Brisbane. 